\title{
PELAKSANAAN PENERIMA KARTU PERLINDUNGAN SOSIAL (KPS) DI KENAGARIAN PUNGGASAN KECAMATAN LINGGO SARI BAGANTI
}

\author{
Juria Asrita \\ ${ }^{1)}$ Prodi Pendidikan Geografi STKIP PGRI Sumatera Barat \\ asritajuria@gmail.com
}

\begin{abstract}
This study aims to identify and analyze the implementation of the card recipient social protection (KPS) in Punggasan village Linggo Sari Baganti District Pesisir Selatan region of: 1) the condition of beneficiary households KPS, 2) Family income recipients KPS and, 3) the availability of water and sanitation family KPS recipients. This type of research is quantitative descriptive. The study population numbered 93 families, whereas for sampling study using total sampling of the number of recipients of total tamplingwith the number $93 \mathrm{KK}$. Data obtained from the relevant agencies, namely, Pesisir Selatan region Social Service, and the results of the field survey.The results showed as follows; 1) The condition of the home receiver KPS in Punggasan village Linggo Sari Baganti District generally uniform, the roofs of zinc, walls and floors of cement, sources of electric lighting, ventilation generally one for each room, a place to store food in a clean, storing food in a clean and not separated and activities MCK in private bathrooms, 2) Income recipients KPS generally $<R p$ 500,000 / month, a side job only occasionally, other family members who have an income is the wife, the average expenditure for staples $<R p$ 500,000 / month and expenses in addition to the basic needs of an average of Rp 100,000 - Rp 200,000 / month and, 3) The provision of clean water KPS recipients generally well, clear water, fresh taste. treatment of water reservoirs clean by draining clean water reservoirs, treatment is done 1 time in 1 week, and the distance of the source of clean water with sewage disposal is generally 25-50 meters.
\end{abstract}

Key Words: implementation, the social protect, KPS

\section{PENDAHULUAN}

Kemiskinan menjadi masalah yang penting saat ini di Indonesia, sehingga menjadi fokus pemerintah Indonesia. Kemiskinan telah membuat jutaan anak tidak bisa mengenyam pendidikan, kesulitan membiayai kesehatan, kurangnya tabungan dan investasi dan masalah lain yang menjurus ke arah tindakan kekerasan dan kejahatan. Kemiskinan yang terjadi dalam suatu Negara memang perlu dilihat sebagai suatu masalah yang sangat serius, karena saat ini kemiskinan membuat banyak masyarakat Indonesia mengalami kesusahan dalam memenuhi kebutuhan hidupnya (Cahyat, dkk, 2007).

Program-program pembangunan dari pemerintah yang bertujuan untuk mengurangi kasus kemiskinan, salah satunya adalah Kartu Perlindungan Sosial (KPS). Kartu Perlindungan Sosial (KPS) adalah kartu yang diterbitkan oleh 
Pemerintah sebagai penanda Rumah Tangga Miskin dan dikeluarkan tahun 2013. KPS memuat informasi Nama Kepala Rumah Tangga, Nama Pasangan Kepala Rumah Tangga, Nama Anggota Rumah Tangga Lain, Alamat Rumah Tangga, Nomor Kartu Keluarga, dilengkapi dengan kode batang (barcode) beserta nomor identitas KPS yang unik (Kementrian Komunikasi dan Informatika, 2011).

Penerima KPS adalah rumah tangga sangat miskin, miskin dan hampir miskin. Hampir miskin adalah keluarga dengan pengeluaran per bulan per kepala antara Rp 233.740.- s/d Rp 280.488.- atau sekitar antara Rp 7.780.- s/d Rp 9.350.per orang per hari. Miskin adalah keluarga dengan pengeluaran per orang perbulan per kepala Rp 233.740.-kebawah atau sekitar Rp 7.780.- kebawah per orang per hari. Sangat miskin adalah keluarga tidak ada kriteria berapa pengeluaran per orang per hari. KPS membantu memastikan agar rumah tangga miskin dan rentan dapat menerima manfaat dari semua Program Perlindungan Sosial yang berhak diterimanya sehingga membantu upaya rumah tangga untuk keluar dari kemiskinan (Sumber: blsm.posindonesia.co.id/kartu.php)

Dampak dari kenaikan BBM, maka pemerintah mengeluarkan kebijakan kenaikan harga BBM dan penyaluran KPS (Kartu Perlindungan Sosial). KPS yang disediakan pemerintah untuk membantu meringankan beban masyarakat miskin, tetapi kegiatan Bantuan KPS tidak jauh dari hal pro dan kontra. Pendapat pro karena bantuan tersebut bisa meringankan beban keseharian para rakyat miskin, terutama di Indonesia dan kontra karena bantuan ini hanya bersifat sementara setelah bantuan ini selesai (Kementrian Komunikasi dan Informatika, 2011).

Penyaluran KPS diharapkan sesuai dengan sasaran, sehingga perlu adanya data valid masyarakat yang berhak menerima KPS. Kepala keluarga yang layak menerima bantuan harus memenuhi karakteristik penerima dan efektifitasnya pemerintah dapat melihat berapa jumlah kepala keluarga yang layak menerima bantuan dan berapa yang tidak layak. Agar tidak terjadi kesalahan seperti program pemerintah sebelumnya, yaitu adanya kesalahan dalam penyaluran, seperti BLT, maka data tentang keluarga sangat miskin, keluarga miskin dan berhak menerima bantuan pemerintah sangat diperlukan (Dinas Sosial, 2014). 
Keberadaan informasi data penduduk miskin sangat penting, karena dengan informasi tersebut pemerintah daerah dapat mengetahui berapa jumlah peduduk miskin yang ada di daerahnya, di kecamatan mana penduduk miskin tersebut berada, seberapa parah tingkat kemiskinan yang dialami dan siapa saja yang telah menerima bantuan dari pemerintah. Data penduduk miskin bertujuan untuk menyajikan informasi yang berkaitan penduduk miskin dan data tersebut dapat digunakan oleh pemerintah sebagai acuan dalam menentukan arah pembangunan di setiap kecamatan yang ada (Ependi, 2014).

Kabupaten Pesisir Selatan memiliki rumah tangga miskin yang berhak untuk menerima KPS sesuai dengan kriteria yang telah ditetapkan. Berdasarkan data Dinas Sosial Kabupaten Pesisir Selatan, Kecamatan Linggo Sari Baganti merupakan penerima terbesar kedua KPS yaitu sebesar 2.930 kepala keluarga. Penerima KPS di Kecamatan Linggo Sari Baganti tersebar di seluruh Nagari yang ada di Kecamatan Linggo Sari Baganti, salah satunya adalah Nagari Punggasan. Nagari Punggasan memiliki 453 KK, sementara KK penerima KPS tercatat sebesar 93 KK (Kantor Wali Nagari Punggasan, 2015).

Berdasarkan observasi awal penulis di nagari Punggasan Kecamatan Linggo Sari Baganti, masih banyak masyarakat yang tidak pantas menerima program KPS mendapatkan bantuan KPS. Begitu pula sebaliknya, banyak masyarakat yang pantas menerima dana KPS tetapi tidak menerima, artinya program KPS di Nagari Punggasan tidak tepat sasaran.

Tujuan penelitian adalah: 1) Kondisi rumah penerima KPS, 2) Pendapatan keluarga KPS dan 3) Ketersediaan air dan MCK keluarga KPS.

\section{METODOLOGI}

Jenis penelitian ini adalah penelitian deskriptif yang bertujuan untuk mengetahui dan mengungkapkan pelaksanaan . Penerima Kartu Perlindungan Sosial (KPS) di Kenagarian Punggasan Kecamatan Linggo Sari Baganti Kabupaten Pesisir Selatan.

Populasi dalam penelitian ini adalah seluruh penerima KPS di Kenagarian Punggasan Kecamatan Linggo Sari Baganti Kabupaten Pesisir Selatan yang berjumlah 93 KK.Sampel penelitian diambil dengan teknik total sampling 
sehingga sampel berjumlah 93 KK. Teknik analisa data pada penelitian menggunakan Analisis persentase dengan rumus ;

$P=\frac{f}{n} \times 100 \%$

\section{PEMBAHASAN}

Pertama: Kondisi rumah penerima KPS di Kenagarian Punggasan Kecamatan Linggo Sari Baganti terdiri dari atap rumah seng yang dimiliki umumnya seng (97,82\%), dinding rumah penerima KPS umumnya kayu $(74,19 \%)$, lantai rumah umumnya semen $(86,02 \%)$, sumber penerangan listrik $(93,55 \%)$. Ventilasi rumah umumnya di ruang tamu $(43,01 \%)$, cara menyimpan makanan siap dikonsumsi umumnya disimpan di tempat khusus dan bersih (97,74\%), cara menyimpan makanan belum siap dikonsumsi umumnya disimpan di tempat khusus, bersih dan dipisahkan $(59,14 \%)$ dan tempat MCK umumnya di kamar mandi sendiri $(83,78 \%)$. Hal ini berarti pelaksanaan KPS di Kenagarian Punggasan sudah tepat sasaran sesuai dengan tujuan yaitu KPS diberikan kepada 25\% Rumah Tangga dengan status sosial ekonomi terendah

Hal ini sesuai dengan kriteria rumah berdasarkan konstruksinya menurut Undang-undang RI No. 1 Tahun 2011 dibedakan menjadi menjadi 3 golongan, yaitu: a) Rumah permanen, memiliki ciri dinding bangunannya dari tembok, berlantai semen atau keramik, dan atapnya berbahan genteng, b) Rumah semipermanen, memiliki ciri dindingnya setengah tembok dan setengah bambu, atapnya terbuat dari genteng maupun seng atau asbes, banyak dijumpai pada gang-gang kecil dan c) Rumah non-permanen, ciri rumahnya berdinding kayu, bambu atau gedek, dan tidak berlantai (lantai tanah), atap rumahnya dari seng maupun asbes.

Lebih lanjut, Notoadmojo (2007: 167-168) menyatakan faktor-faktor yang perlu diperhatikan dalam membangun suatu rumah: 1) Faktor lingkungan, baik lingkungan fisik, biologis maupun lingkungan sosial. Maksudnya membangun suatu rumah harus memperhatikan tempat dimana rumah itu didirikan, baik di pegunungan atau di tepi pantai, di desa atau di kota, di daerah dingin atau di daerah panas, di daerah pegunungan dekat gunung berapi (daerah gempa) atau di 
daerah bebas gempa dan sebagainya. Rumah didaerah pedesaan tentu disesuaikan kondisi sosial budaya pedesaaan, misalnya bahan yang di gunakan, bentuknya, menghadapnya, dan lain sebagainya. Rumah didaerah gempa harus dibuat dengan bahan-bahan yang ringan namun harus kokoh, rumah didekat hutan harus dibuat sedemikian rupa sehingga aman terhadap serangan-serangan binatang buas. 2) Tingkat kemampuan ekonomi masyarakat. Hal ini dimaksudkan rumah dibangun berdasarkan kemampuan keuangan penghuninya, untuk itu maka bahan-bahan setempat yang murah misal bambu, kayu atap rumbia dan sebagainya adalah merupakan bahan-bahan pokok pembuatan rumah. Perlu dicatat bahwa mendirikan rumah adalah bukan sekadar berdiri pada saat itu saja, namun diperlukan pemeliharaan seterusnya

Kedua: Pendapatan Penerima KPS di Kenagarian Punggasan Kecamatan Linggo Sari Baganti Kabupaten Pesisir Selatan, dimana pendapatan perbulan penerima KPS umumnya < Rp 500.000 (59,14\%), pemenuhan kebutuhan dari pendapatan umumnya pas-pasan $(52,69 \%)$, penghasilan sampingan kadangkadang ada $(83,87 \%)$, jenis usaha sampingan umumnya petani $(41,94 \%)$, jumlah penghasilan sampingan umumnya $<\operatorname{Rp} 500.000$ (83,87\%), sumber penghasilan anggota keluarga umumnya sebagai petani $(59,14 \%)$, anggota keluarga yang memiliki penghasilan umumnya istri $(72,04 \%)$, jumlah penghasilan anggota keluarga/bulan umumnya < Rp 500.000 (74,19\%), pengeluaran untuk kebutuhan pokok umumnya < Rp $500.000(58,06 \% 0$ dan pengeluaran selain kebutuhan pokok umumnya Rp 100.000 - Rp 200.000/bulan (44,09\%).

Hal ini sesuai dengan pendapat Sheraden (2006:23) bahwa pendapatan merupakan semuan uang yang masuk dalam sebuah rumah tangga atau unit terkecil lainnya dalam suatu masa tertentu. Ini disebut sebagai arus mengalirnya (flow) uang. Pendapatan seseorang bisa didapat dari tiga sumber utama: perusahaan, aset, dan santunan (transfer).

BPS (2008) pendapatan adalah merupakan balas jasa yang diterima oleh faktor-faktor produksi dalam jangka waktu tertentu . Balas jasa tersebut dapat berupa sewa, upah atau gaji, bunga uang ataupun laba. Dilihat dari pemanfaatan tenaga kerja pendapatan yang berasal dari balas jasa berupa upah atau gaji di sebut 
dengan pendapatan tenaga kerja (labor income). Sedangkan pendapatan dari balas jasa selain tenaga kerja disebut dengan pendapatan bukan tenaga kerja (non laborincome). Disamping itu ada pula pendapatan yang bukan berasal dari balas jasa atas pemanfaatan faktor produksi dan tidak bersifat mengikat. Pendapatan ini disebut pendapatan transfer. Pendapatan transfer ini (transfer income) dapat berasal dari pemberian perseorangan atau institusi (misalnya pemerintah). Pendapatan transfer ini dapat positif maupun negatif tergantung pada besarnya pembayaran atau penerimaan transfer dalam jangka waktu tertentu.

Ketiga, penyediaan air bersih meliputi sumber air bersih yang digunakan sumur $(84,95 \%)$, warna air yang digunakan air berwarna bening $(90,32 \%)$, rasa air yang digunakan tawar $(93,55 \%)$. Perawatan tempat penampungan air bersih dengan cara menguras tempat penampungan air bersih $(86,02 \%)$, perawatan 2 kali/minggu $(58,06 \%)$ dan jarak tempat pembuangan air bersih dengan tempat pembuangan kotoran umumnya 25 - $50 \mathrm{~m}(63,44 \%)$.

Syarat kualitas air bersih berdasarkan Kemenpera (2001), bahwa: 1) Syarat Fisik : Tidak berbau, tidak berasa, dan tidak berwarna, 2) Syarat Kimia: Kadar Besi : maksimum yang diperbolehkan 0,3 mg/l, Kesadahan (maks 500 mg/l) dan 3) Syarat Mikrobiologis : Koliform tinja/total koliform (maks 0 per 100

Selanjutnya Eliza(2008) macam dan sumber air adalah hal yang sangat pokok jika membicarakan air dan kaitannya dengan kesehatan. Macam air berdasarkan sumber atau asalnya dapat dibedakan atas: 1) air hujan, embun, salju yakni air yang didapat dari angkasa, karena terjadinya proses presipitasi dari awan, atmosfer yang mengandung uap air. 2) air permukaan tanah, yang dapat berupa air yang tergenang atau air yang mengalir, seperti danau, sungai, laut, air dari sumur dangkal adalah juga air dari permukaan tanah. 3) air dalam tanah, yakni air permukaan tanah yang meresap kedalam tanah, jadi telah mengalami penyaringan oleh tanah ataupun batu-batuan. Ditinjau dari sudut kesehatan, ketiga macam air ini tidaklah selalu memenuhi syarat kesehatan, karena ketiga-tiganya mempunyai kemungkinan untuk dicemari

\section{KESIMPULAN}


1. Kondisi rumah penerima KPS di Kenagarian Punggasan Kecamatan Linggo Sari Baganti berdasarkan hasil penelitian umumnya seragam, yaitu atap rumah dari seng, dindingdarikayu, lantai dari semen, sumber penerangan listrik, ventilasi umumnya 1 untuk setiap ruangan, tempat penyimpan makanan pada tempat yang bersih, menyimpan bahan makanan di tempat yang bersih bersih dan, tidak dipisah serta melakukan aktivitas MCK di kamar mandi pribadi.

2. Pendapatan penerima KPS umumnya < Rp 500.000/bulan, pekerjaan sampingan hanya kadang-kadang, anggota keluarga lainnya yang memiliki penghasilan adalah istri, pengeluaran rata-rata untuk kebutuhan pokok $<\mathrm{Rp}$ 500.000/bulan dan pengeluaran selain kebutuhan pokok rata-rata Rp 100.000 Rp 200.000/bulan.

3. Penyediaan air bersih penerima KPS terdiri dari sumber air bersih yang digunakan umumnya sumur, air bening, rasa tawar. perawatan tempat penampungan air bersih dengan cara menguras tempat penampungan air bersih, perawatan dilakukan 1 kali dalam 1 minggu, dan jarak sumber air bersih dengan tempat pembuangan kotoran umumnya 25-50 meter.

\section{DAFTAR PUSTAKA}

Anonimus. 2008. NMC CSRRP DI Yogyakarta, Central Java and West Java 1. PedomanPerencanaan MCK (MandiCuciKakus) KomunalUntukProyek REKOMPAK - JRF.

Arikunto. 2006. ProsedurPenelitian. Jakarta :RinekaCipta

BadanPusatStatistik. 2004. Survey SosialEkonomiNasional.

Badan Pusat Statistik, 2008, Analisis dan Penghitungan Tingkat Kemiskinan Tahun 2008, Jakarta: BPS. www.bps.go.id

blsm.posindonesia.co.id/kartu.php

Cahyat, Ade, CristianGonner\&MichaleaHaug.2007. MengkajiKemiskinandanKesejahteraanRumahTangga.Bogor: CIFOR.

DepartemenKesehatan RI. 2004. BukuSakuRumahTanggaSehatdengan PHBS, Jakarta

DepartemenSosial RI. 2004. BukuSakuRumahTanggaSehatdengan PHBS, Jakarta 
Ependi, Usman. 2012. “Sistem Informasi Pemetaan Data Penduduk Miskin Di Kabupaten Ogan Komering Ulu Sumatera Selatan”. Jurnal Digital Information \& System.

Febrian, Kiki.2014. "Persepsi Masyarakat tentang Badan Penyelenggara Jaminan Sosial (BPJS) di kenagarian Pauh kecamatan Lubuk Sikaping kabupaten Pasaman". Skripsi, Program StudiPendidikanGeografi STKIP PGRI Sumatera Barat

KementrianKomunikasidanInformamatika. 2011. Program

PenanggulanganKemiskinanKabinet Indonesia Bersatu 1

Notoadmodjo, Soekidjo, 2007. KesehatanMasyarakat . Jakarta: RinekaCipta.

PunggasandalamAngka, 2014.

Othman, Mumtazah. 1988. PengurusanSumberKeluarga. Malaysia: DewanBahasadanPustaka

PusatPenelitiandanPengembanganPermukiman,

BadanPenelitiandanPengembangan. 2001. Tata Cara PerencanaanBangunan MCK komunal/umum. Penerbit: Kimpraswil,

DepartemenPermukimandanPrasarana Wilayah.

DepartemenPermukimandanPrasarana, Bandung.

Sherraden, Michael. 2006. AsetUntuk Orang Miskin.Jakarta: Raja Grafindo.

Sukarni, Mariyati. 1994. KesehatanKeluargaLingkungan. Konisus. Bogor

$\begin{array}{lllll}\text { Undang-undang } & \text { RI } & \text { No. } & 1 & \text { Tahun }\end{array}$ tentangPerumahandanKawasanPermukiman.

Triyono. 2013." Kendala kepesertaan Program Jaminan Sosial terhadap Pekerja di Sektor Informal: studi kasus di kota Surabaya”. Skripsi. Unair Surabaya Yusuf, Muri. 2005. MetodologiPenelitian. Padang .Padang:UNP Pers

Wilmawitawilmawita, drs.Dasrizal, mpdrs.Dasrizal, mp, widyaprarikeslan. (2014). The role communities in the national program for commumity empowerment (pnpm-m) in district kinali west pasaman.STKIP PGRI Sumatera Barat.http://ejournal-s1.stkip-pgrisumbar.ac.id/index.php/geografi/article/view/1921.13:09 